\title{
An Analysis of the Image of Yukiko in The Makioka Sisters
}

\author{
Zhengdong $\mathrm{Xu}$ \\ College of Foreign Languages \\ Guizhou University \\ Guiyang, China
}

\begin{abstract}
Japanese aesthetic novelist Junichiro Tanizaki's novel The Makioka Sisters, takes the protagonist - Yukiko 's blind dates as the main clue to describe the story of the famous Osaka family called Makioka in the period of the Second World War. The novel portrays four distinct female characters-Tsuruko, Sachiko, Yukiko, and Taeko. This paper hopes to make a brief analysis of Yukiko's image through the interpretation of the original text.
\end{abstract}

Yukiko is a shy, traditional Japanese female, who is always favored by the people around her. In everyone's mind, Yukiko is the representative of beauty and purity. The author Junichiro Tanizaki also praises this kind of female image and classical beauty. In contrast, her sister Taeko's image is totally different. She deviates from the tradition, and makes a living by herself, falls in love and marries freely. She pursues her own happiness. Taeko represents a completely different kind of female thought and interest of life in the new era. On the one hand, Junichiro Tanizaki praises the traditional Japanese classical feminine beauty; on the other hand, he affirms the change of feminine thought when the new era comes.

\section{Keywords-Yukik; Taek; image analysis; traditional beauty}

\section{INTRODUCTION}

The main characters appeared in Tanizaki's novel The Makioka Sisters are Tsuruko, Tatsuo, Sachiko, Teinosuke, Etsuko, Yukiko, Taeko, etc., as well as the landlady of beauty shop - Itani, Mrs. Jinba, Mrs. Nyu, Doctor Kushida, Okubata, Itakura, Miyoshi and so on. In the novel, the couple of Tsuruko mainly lived in the old house of Nagamotocho, and later moved to Shibuya, Tokyo. Sachiko and her husband live in Ashiya city, and Yukiko also lives there, she sometimes lives in the house of her sister Tsuruko in Tokyo. Taeko rents an apartment outside, and sometimes stays at her sister Sachiko's house.

The activities of the four sisters in the novel are mainly centered on Yukiko's marriage. Tsuruko replies to Yukiko's every marriage by letters and is responsible for the man's family background investigation. Sachiko coordinates the relationship between her sisters and helps Yukiko in blind dates. She experienced abortion and once went to Kyoto to enjoy cherry blossoms. Yukiko went back and forth between her second sister Sachiko and eldest sister Tsuruko's home in Tokyo. She likes reading books, writing, studying flower arrangement and tea ceremony, she finally married an aristocratic descent called Mimaki. Taeko made three boyfriends successively. For the first time, Okubata and she became the headline in the newspaper for elopement, which had a negative impact on Yukiko's reputation. Later, when the flood broke out, she felt good about Itakura's (servant from Okubata family) rescue and pledged to marry him without parental permission. After the death of Itakura, she used Okubata and Okubata was expelled from his home and left in exile. Finally, the baby of Miyoshi was found dead after childbirth. She studied country dance, suit making, doll making and so on. She tried to make herself financially independent and wanted to study in France once and survived the flood and malignant dysentery. The main plot of the novel revolves around Yukiko's marriage.

\section{FOUR UNSUCCESSFUL BLIND DATES OF YUKIKO}

From the content of the novel, the first volume of the novel describes Yukiko's first two unsuccessful blind dates. The second volume describes Taeko, Sachiko, Itakura, flood, typhoon and other trifles of life. The third volume describes Yukiko's third and fourth blind dates, Taeko's pregnancy, and Yukiko's final selection. From the length of Yukiko, it can be found that there are few stories about Yukiko in the first volume of the novel. Yukiko only appears in readers' eyes when the plot goes on a blind date. The description of Yukiko in the second volume is also very few. There are only two descriptions. One is Yukiko's visiting relatives and returning home after the flood in Ashiya city, and the other one is about Taeko's Dance. In a word, Yukiko herself seems not very interested in blind dates. There are few descriptions about her and more are other people's speculations about Yukiko's thoughts. The following parts are the content of Yukiko's four unsuccessful blind dates. From the four unsuccessful blind dates, it can get a general understanding of Yukiko's specific image in the novel.

When Yukiko met Segoe in the first blind date, people around her were worried about the brown spots on her forehead. Yukiko didn't seem to care about it. When the man asked her to take an X-ray check and provide a health report, Yukiko also agreed. At the same time, Segoe was also investigated by Yukiko's eldest sister and finally he was found a family history of psychosis. When Sachiko told Yukiko that the marriage had been failed, she was still as if nothing had happened. Yukiko just asked her sister "Is that 
really so?" It can be found that Yukiko is a young woman who does not emphasize initiative and tends to accept other people's arrangements.

On the second blind date, Mrs. Jinba introduced Yukiko to Minokichi Nomura. Sachiko helped her even she was sick at that time. After the appointment, Sachiko asked Yukiko how she felt. She just answered "uh" and said nothing. When she ran into Nomura in the shop, she was very nervous and could not even say a word. Finally, she asked her sister to refuse the marriage. As the reason, she said, when she visited Nomura's residence, the photos of Nomura's deceased wife and two deceased children were placed in a conspicuous place, which aroused Yukiko's disgust. It can be found from this example that Yukiko is a shy lady who is not good at communicating with strangers on her own.

The third volume begins with Yukiko's third blind date, which with Sawazaki. After the meeting, Yukiko went to Tokyo. On the way, she met Saigusa, one man who met her about ten years ago on the first unsuccessful blind date. Saigusa kept looking at Yukiko on the train, which reminded her of the refusal to the marriage. At that time, Tatsuo, the brother-in-law, tried his best to bring them together, while eventually failed. As said in the sixth chapter of the novel, "Yukiko never express her opinion obviously, but only gave other people ambiguous answers. She would not express her refusal until her brother-in-law was in trouble" [1]. Yukiko always expresses her agreement or refusal to a marriage in a less obvious way, which is consistent with her performance in the previous two blind dates.

The fourth blind date is with Fukutaro Hashidera, the director of a pharmaceutical company. After the meeting, Yukiko left a gloomy impression on the man. The failure of this blind date is due to a telephone call between Yukiko and Hashidera. One day, Hashidera called Yukiko to invite her for a walk. While Yukiko never answer the phone by herself, in the panic, she asked Haru, the maid, to call out for Sachiko to answer the phone. Then in the desperation, Yukiko answered the phone by herself and hesitated to answer the man's questions, which was regarded as rude by Hashidera. Sachiko was angry and annoyed with Yukiko's mistake, while she was reading books and playing with cats in the upstairs room as if nothing had happened after the incident. When her sister Sachiko saw that, she felt compassionate for Yukiko and did not blame her again. From the descriptions of four unsuccessful blind dates above, it can be found that Yukiko is introverted and shy in marriage. This kind of image runs through the whole novel from the beginning to the end.

\section{THE ANALYSIS OF THE IMAGE OF YUKIKO}

With regarding to the space occupied by each character's activities in the novel, the order is Tsuruko, Yukiko, Taeko, Sachiko. Sachiko and her husband's activities occupied the largest space, followed by Taeko. As the protagonist of the four unsuccessful blind dates, the description about Yukiko is not the most. The eldest sister, Tsuruko appears very few. From the text of the novel, it can also be known that the direct description of Yukiko is relatively less.
As for the characters in the novel, from the above content, it can be found that the author positioned Yukiko as a shy Japanese classical female. Yukiko seems to be a representative of classical beauty. She always appears in kimono in the whole novel, which may be related to Tanizaki's propaganda of traditional beauty. On the contrary, her sister Taeko usually wears a suit and wants to be a professional woman, which is quite different from Yukiko's life interest and ideal. From the clothing of the two sisters, it can be seen that they represent different life ideals and beauties. Yukiko and Taeko seem to be representatives of traditional beauty and modern beauty. At the same time, one detail that deserves the attention in this article is that every time the family will help Yukiko select the candidates very carefully and their purpose is to ensure the happiness of Yukiko's life. In fact, these actions seem to symbolize the maintenance of traditional beauty. In the eighth chapter of the third volume of the novel, it is written obviously that "After all, father likes women like Kyoto's Beauty...among sisters, Sachiko likes Yukiko more than Taeko, the main reason is that Yukiko is the one who most like mother among the four sisters...the advantages of mother's temperament and appearance, Yukiko inherits a lot. Even the fragrance emanating from mother can be smelled slightly from Yukiko". [2] In Chapter 9, it is also written like that "Because of this, people have more compassion for this girl. It's ridiculous that such an innocent girl should always be left alone in her empty house. How sad will the deceased father and mother be in heaven?" [3]. From these comments, it can be seen that the author intentionally or unintentionally maintains and advocates this kind of traditional beauty. The protagonist - Yukiko is the representative of this kind of beauty. For this kind of traditional classical beauty, the author thinks that it is necessary to take care of it, which reflects the author's aesthetic view.

With regarding to Yukiko's character, in Chapter 17 of Volume 3, Teinosuke said, "I didn't mean that, I mean a woman who is passive and conservative like Yukiko and even can't make a good phone call must have her own unique strengths. There may be a man in the world who does not regard her character as being old-fashioned, but as a kind of gentle and noble quality. A man who can't recognize her virtues is not qualified to be her husband". [4] This passage summarizes Yukiko's personality, and the author seems to express a kind of appreciation for this kind of female image through the words of the characters in the novel. Of course, Yukiko is not always a coward. At the end of the story, Taeko falls in love with Miyoshi, the head of the bar. When she planned to abandon Okubata, Yukiko revealed the scandal that Taeko did outside, which also shows another aspect of Yukiko's personality.

The uniqueness of this novel lies in the contrast between Yukiko and Taeko. Yukiko represents the traditional feminine beauty of Japan, while Taeko represents the feminine thought of the new era. Yukiko is shy and talks little. She doesn't express thoughts at will, and her marriage is arranged by family. Taeko deviates from the traditional ways, wants to make a living on her own, and actively seeks love. She met many men outside, such as Okubata, Itakura, 
Miyoshi, and finally abandoned Okubata, and conceived Miyoshi's child. Compared the two sisters, Taeko is active while Yukiko is passive, and her marriage is arranged by other people. On the relationships between them, Yukiko is in harmony with her sisters, Sachiko, Tsuruko and Taeko. She is loved by everyone. However, Taeko often conflicts with her sisters, she once ran away from home, went abroad, experienced Itakura's death and so on. It can be said that Taeko's image corresponds to that of Yukiko. The author's arrangement of Taeko and Yukiko's different life circumstances also seems to advocate the opposition between traditional classical beauty and modern women's thought. Chapter 26 of Volume 2 of the novel says, "Anyone knows that Yukiko is pure. Even if the family is investigated, there would be no shortcomings or gossip to be said about her, while her queer-tempered sister Taeko is easily noticeable". [5] Chapter 27 says, "Sachiko often thinks of Yukiko who is living a lonely life in Tokyo. Yukiko's personality is different from that of Taeko, who ignores other people's dilemmas and opinions and does what she likes. Yukiko, on the contrary, is totally lacking in initiative". [6] All these show the difference between them, and the author's aesthetic view is expressed in many ways through the content of the novel.

Regarding the images of other characters in the novel, Taeko and her husband are intermediaries coordinating sisterhood. She is neither conservative nor deviant like Taeko. The eldest sister, Tsuruko, is a conservative representative. Whether the candidate is suitable or not requires the consent of her and her husband. In a word, the novel describes four different female characters. Through the analysis, it can be found that the tendency of conservative tradition is weakening from the eldest sister to the fourth sister, and the new feminine thought is gradually strong, which can be seen as the alternation of old and new feminine thought at that time.

\section{CONCLUSION}

As a novel with the background of the Second World War, Tanizaki's The Makioka Sisters seldom describes the war. The novel creates a unique story environment. The four sisters and their family seem to be divorced from the real society and live a comfortable, peaceful and beautiful life. The background of the story seems to have nothing to do with the reality. On the style of this novel, it is fresh and free from vulgarity, which can evoke readers' good memories of the past.

This novel describes the lives of the four sisters of the Makioka family around the marriage of Yukiko. From Yukiko's four unsuccessful blind dates, it can be known that she is a shy, traditional Japanese female. The protagonist with these characters is favored by the people around her. In everyone's mind, Yukiko is the representative of beauty and purity. The author praises this kind of female image and classical beauty in various ways. In contrast, Taeko's image is totally different. She deviates from the tradition, makes a living by herself, falls in love and marries freely. She pursues her own happiness. It can be found that Taeko represents a completely different kind of female thought and interest of life in the new era.
From the analysis of this novel, the author's purpose of setting up two different roles, Yukiko and Taeko, can be gradually found. On the one hand, he advocates and praises the traditional Japanese classical feminine beauty, on the other hand, he affirms the change of feminine thought when the new era comes. Although there are few direct descriptions of Yukiko in the novel, the image of Yukiko is perfectly sketched through other descriptions. Generally speaking, the author advocates this kind of traditional feminine beauty. On Yukiko's fourth blind date, she couldn't answer the phone by herself, the blind date failed because of that, while her sister, Sachiko and the family didn't blame her, which further illustrates the author's maintenance of this kind of traditional beauty. Yukiko represents the classic, while Taeko represents the new trend of thought, the new era, they are completely different life trajectories.

\section{REFERENCES}

[1] Junichiro Tanizaki, The Makioka Sisters, Tokyo: Chuokoron-shinsha, Inc., pp.627, 2015.

[2] Junichiro Tanizaki, The Makioka Sisters, Tokyo: Chuokoron-shinsha, Inc., pp.640-641, 2015.

[3] Junichiro Tanizaki, The Makioka Sisters, Tokyo: Chuokoron-shinsha, Inc., pp.644, 2015.

[4] Junichiro Tanizaki, The Makioka Sisters, Tokyo: Chuokoron-shinsha, Inc., pp.732, 2015.

[5] Junichiro Tanizaki, The Makioka Sisters, Tokyo: Chuokoron-shinsha, Inc., pp.480, 2015.

[6] Junichiro Tanizaki, The Makioka Sisters, Tokyo: Chuokoron-shinsha, Inc., pp.485, 2015.

[7] Junichiro Tanizaki, Chu Yuanxi (translator), The Makioka Sisters, Shanghai: Shanghai Translation Press, 2011.

[8] Cui Xianglan, Zhang Lei, New Japanese literature history, Dalian: Dalian University of Technology Press, 2015.

[9] Tan Jinghua, Appreciation of Japanese modern literature masterpieces, Shanghai: Shanghai Foreign Language Education Press, 2003.

[10] Tan Jinghua, History of modern Japanese literature, Shanghai: Shanghai Foreign Language Education Press, 2010. 